Radioprotection, vol. 46, $\mathrm{n}^{\circ} 6$ (2011) S3-S5

(C) EDP Sciences, 2011

DOI: $10.1051 /$ radiopro/20116451s

\title{
Long-term survey of Caesium-137 in soil and grass
}

\author{
W. Ringer, J. Klimstein, M. Bernreiter and J. Gräser \\ Competence Centre for Radioecology and Radon (CC-RARA), Austrian Agency for Health \\ and Food Safety (AGES), Wieningerstrasse 8, 4020 Linz, Austria
}

\begin{abstract}
The construction and start-up of the Czech nuclear power plant in Temelin led to a substantial uncertainty and opposition among the Austrian population. For this reason a specific monitoring programme was started in the federal state of Upper Austria in 1992. Within this programme regularly soil, grass, precipitation, cereals, and raw milk from different locations are sampled and measured. Furthermore, insitu gamma spectrometric measurements of grassland are conducted yearly. This poster presents some of the results from the monitoring of soil and grass. Soil and grass samples are collected from seven sites on a yearly basis. Samples from six layers $(0-5 \mathrm{~cm}, 5-10 \mathrm{~cm}, \ldots)$ are taken to investigate the change of the vertical profile of the Cs- 137 concentration over time. Measurements were done by high-resolution gamma spectrometry and liquid scintillation counting (Sr-90).
\end{abstract}

\section{RESULTS AND DISCUSSION}

\subsection{Time series and depth profile of Cs-137 in soil}

Figure 1 gives the time series from 1992 to 2010 and depth profiles of Cs-137 in soil at seven sampling sites. There is a general trend to lower Cs-137 activity concentrations in the first layer and - depending on the soil characteristics - a more or less pronounced migration to deeper layers can be observed. Factors controlling migration are e.g. soil texture, soil density, macro pores, mineralogy, clay content, precipitation and they are different for the sampling sites [1]. In 2010 the Cs-137 activity concentration was already higher in the second layer than in the first layer at four sampling sites.

\subsection{Local variation of Cs-137 in soil - detection limits for new depositions}

Small scale local variation can be high for Cs-137 even on undisturbed grasslands whereas K-40 is rather homogenous both in horizontal and vertical directions (see Figure 2). Due to the Cs-137 background, its site-specific small scale variation, and the limited number of samples taken from one site ( $\mathrm{n}=5$ in this study) a kind of detection limit was calculated for each sampling site (based on [2]) above which a new deposition can be recognised reliably. Given the results, only an increase of Cs-137 of more than 50 to $100 \%$ (depending on the sampling site) can be considered as a new deposition.

\subsection{Time series of Cs-137 in grass - ecological half-lives}

The time series of Cs-137 and K-40 in grass at the sampling site in Freistadt gives a rather neat graph with decreasing activity concentrations for Cs-137 (Figure 3). However, ecological half-lives obviously depend on the observation period and are only significant for the sampling sites in Freistadt, Sandl, and Schöneben (Table 1). 

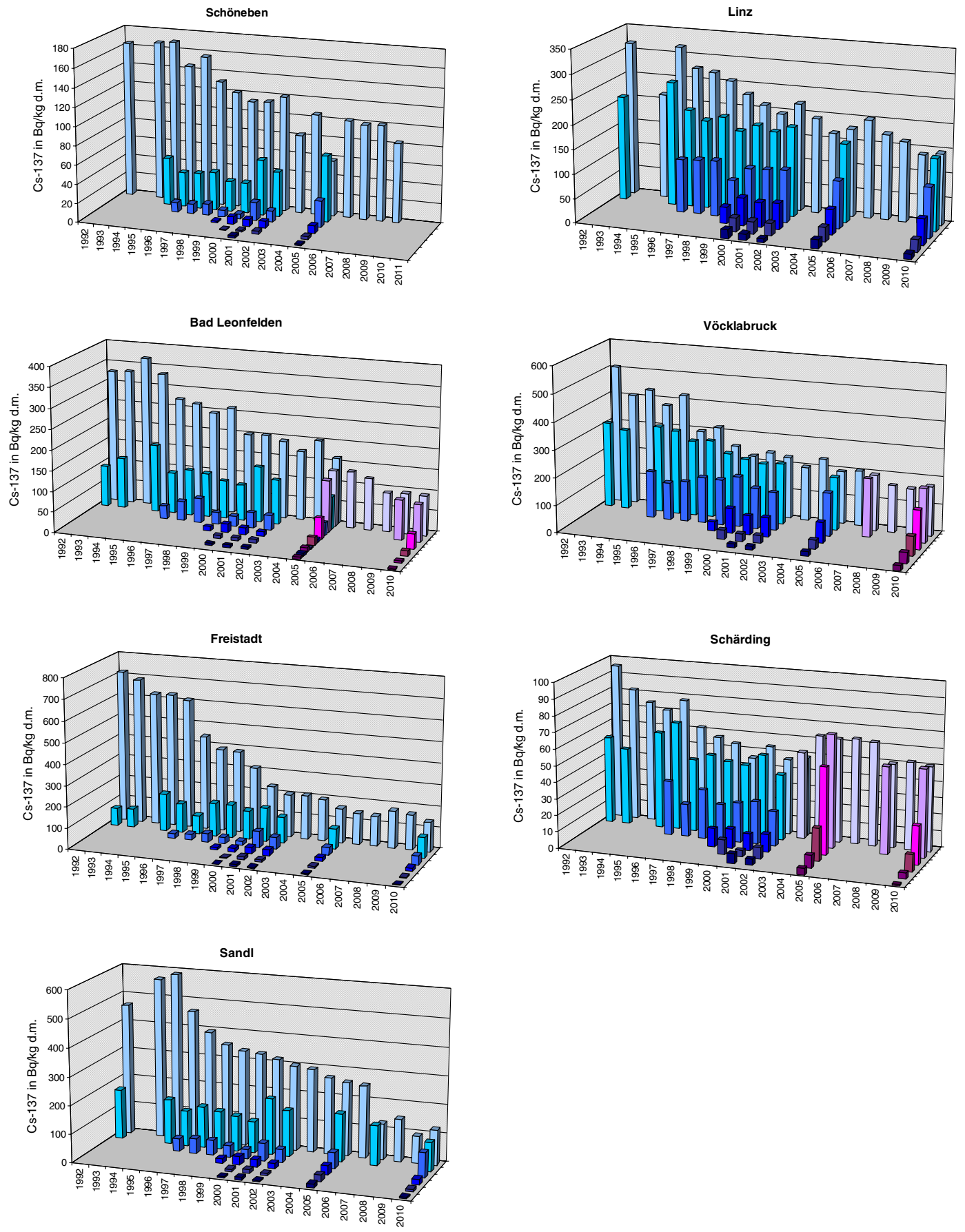

Figure 1. Time series and depth profile (6 layers à $5 \mathrm{~cm}$ ) of Cs-137 in soil at seven locations; a change of sampling location within the same community took place in Bad Leonfelden (2005), Vöcklabruck (2007), and Schärding (2003). 

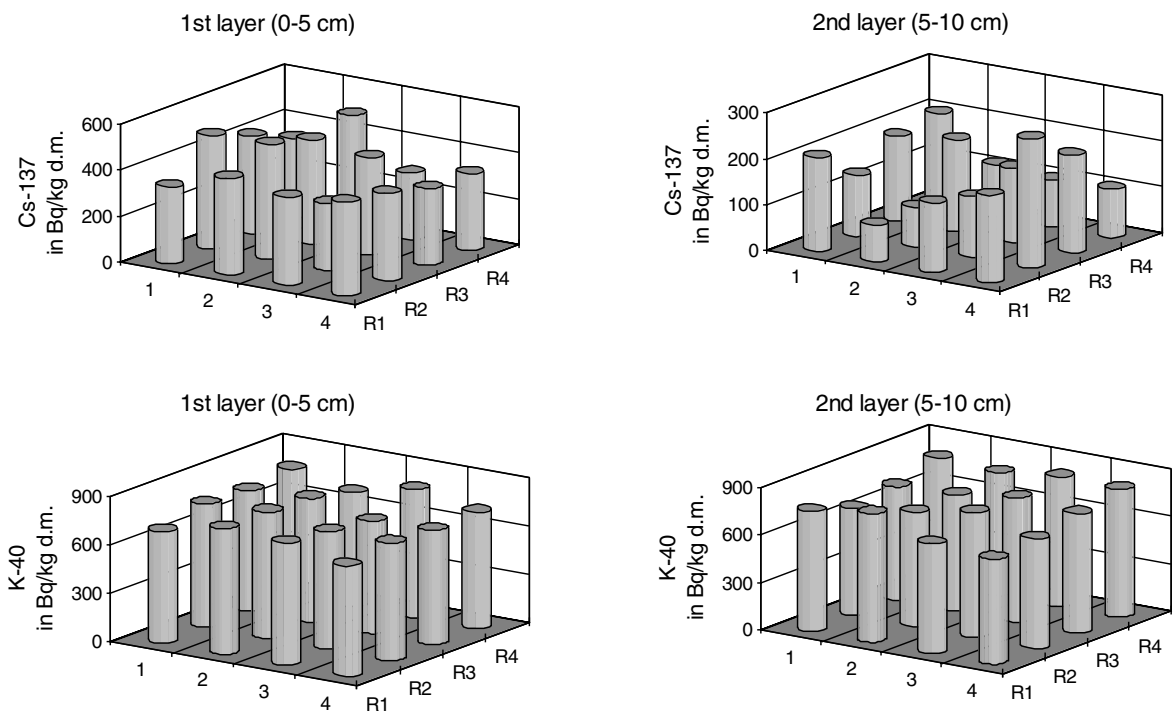

Figure 2. Small scale variability of Cs-137 and K-40 in the first two soil layers at the sampling site in Freistadt (sampling area $9 \times 9 \mathrm{~m}, 16$ samples).
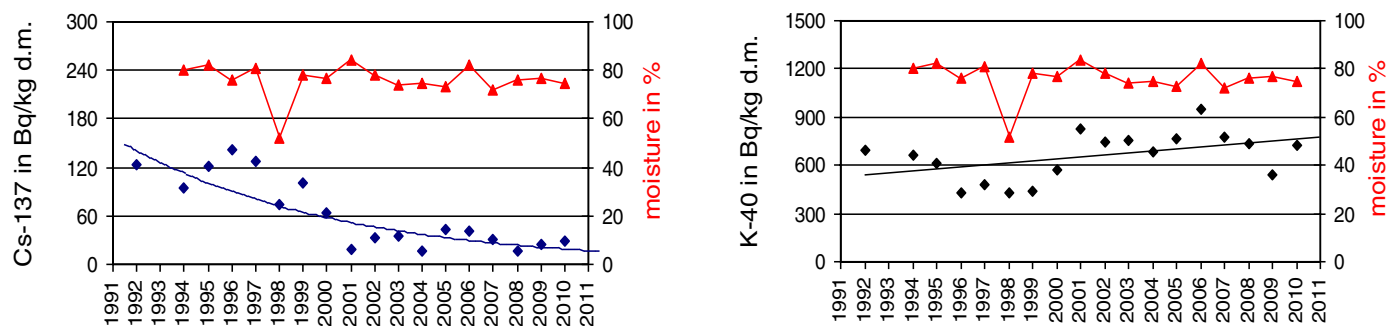

Figure 3. Time series of Cs-137 and K-40 at the sampling site in Freistadt from 1992 to 2010 (rhombus: Cs-137, triangle: moisture).

Table 1. Ecological half-lives calculated for three periods [from 3, 4, 5].

\begin{tabular}{|l|c|c|c|}
\hline & $1992-2001$ & $1992-2004$ & $1992-2010$ \\
\hline Bad Leonfelden & $-15.3 \pm 36.94$ & $-33.9 \pm 92.9$ & \\
\hline Freistadt & $10.5 \pm 6.5$ & $7.4 \pm 2.5$ & $7.9 \pm 1.8$ \\
\hline Linz & $-185 \pm 2800$ & $17.1 \pm 16.3$ & $71 \pm 4473$ \\
\hline Sandl & $3.0 \pm 0.8$ & $6.5 \pm 2.9$ & $15.5 \pm 11.0$ \\
\hline Schärding & $-17.7 \pm 65.6$ & $107 \pm 1176$ & \\
\hline Schöneben & $14.2 \pm 7.5$ & $11.0 \pm 3.0$ & $14.9 \pm 3.9$ \\
\hline Vöcklabruck & $7.6 \pm 2.9$ & $10.4 \pm 3.8$ & \\
\hline
\end{tabular}

\section{References}

[1] Strebl F., Ringer W., Gerzabek M.H., Journal of Environmental Radioactivity 58, 143-161 (2002)

[2] Lettner H., Bossew P., Hubmer A.K., UBA-94-101, Wien, October 1994

[3] Pröhl G. et al, Bundesamt für Strahlenschutz, Abschlussbericht St.Sch. 4276, July 2003

[4] Pröhl G. et al, Journal of Environmental Radioactivity 91, 41-72 (2006)

[5] Kirchner G., personal communication, April 2011 